\title{
Perspective on calf and mammary gland development through changes in the bovine milk proteome over a complete lactation
}

\author{
Lina Zhang, ${ }^{*}$ Sjef Boeren, $†$ Jos A. Hageman, $¥ \S$ Toon van Hooijdonk, ${ }^{*}$ Jacques Vervoort, $\dagger$ \\ and Kasper Hettinga*1 \\ *Dairy Science and Technology, Food Quality and Design Group, Wageningen University, Bornse Weilanden 9, 6708 WG, Wageningen, \\ the Netherlands \\ †Laboratory of Biochemistry, Wageningen University, Dreijenlaan 3, $6703 \mathrm{HA}$, Wageningen, the Netherlands \\ $\ddagger$ Biometris-Applied Statistics, and \\ $\S$ Centre for BioSystems Genomics, Wageningen University, Droevendaalsesteeg 1, 6708 PB Wageningen, the Netherlands
}

\begin{abstract}
Milk contains all the nutrients for the growth and development of the neonate. However, milk composition is not constant during lactation. To study the changes of the milk proteome over lactation, filter-aided sample preparation combined with dimethyl labeling followed by liquid chromatography tandem mass spectrometry was used to identify and quantify milk proteins from 4 cows. A total of 229 proteins were identified, of which 219 were quantified. An $80 \%$ overlap was found in identified and quantified proteins between the 4 individual cows during lactation. Over lactation, the number of quantified proteins changed slightly (less than 10\%), whereas the concentration of proteins changed considerably. Transport proteins involved in lipid synthesis (fatty acid-binding protein, perilipin-2, butyrophilin) increased, whereas proteins related to cholesterol transport (apolipoprotein E) decreased. The changes of lipid synthesis proteins are in accordance with the increased milk fat yield over lactation, indicating the increase of de novo mammary fatty acid synthesis as lactation advances. The high abundance of immune-related proteins in early lactation indicates the important role of these proteins for immune system development of calves. The increase in immune-related proteins (immunoglobulins, osteopontin, lactoferrin) and the decrease of proteins related to milk component synthesis ( $\alpha$-lactalbumin, $\beta$-lactoglobulin, fatty acid-binding protein, perilipin-2, butyrophilin) in late lactation can be associated with the protection of the mammary gland. In conclusion, the changes of proteins with different biological functions reflect not only the changing needs of calves but also the development and protection of the mammary gland over lactation.
\end{abstract}

Received January 15, 2015.

Accepted April 26, 2015.

${ }^{1}$ Corresponding author: kasper.hettinga@wur.nl
Key words: bovine milk proteome, lactation, immunerelated proteins, mammary gland

\section{INTRODUCTION}

Milk provides complete nutrition and bioactive proteins, which are essential for not only the development but also the health benefits of newborns (German and Dillard, 2006; Casado et al., 2009). Breast milk has been considered as the best food for infants (Lonnerdal, 2010). Because of a variety of reasons, a certain number of babies will not get breast milk and will therefore rely on infant formula for survival. Infant formula is developed with bovine milk as a protein source for mimicking human milk (Hernell, 2011). The differences in composition between human milk and bovine milk (D'Auria et al., 2005) have been shown to result in different health benefits of infants fed with breast milk or infant formula; for example, breastfed infants have fewer infections (gastrointestinal infections, acute otitis media) and reduced risk for celiac disease, obesity, and diabetes compared with formula-fed infants (Dewey, 2001; Hernell, 2011).

Recent developments in proteomic techniques have led to an interest in the bovine milk proteome. Previous research identified milk proteins in bovine colostrum and mature milk (D'Alessandro et al., 2011; Nissen et al., 2012; Sacerdote et al., 2013), and the quantitative differences in the milk proteome between bovine colostrum and mature milk (Stelwagen et al., 2009; Zhang et al., 2015). So far, however, variation has not been studied in these low-abundant proteins in mature bovine milk over the whole lactation (from early to the end of lactation). In addition, previous studies on the bovine milk proteome did not take into account individual differences nor was variation of milk proteome between individual cows examined over a full lactation period.

Such a comprehensive study of the variation in lowabundant proteins of bovine milk over lactation is expected to not only contribute to our understanding of 
the needs of calves over lactation but also to increase our understanding of the involution of the mammary gland and mastitis. Therefore, the objective of this study was to determine the qualitative and quantitative variation in the milk proteome from 4 individual cows from early to late lactation using proteomic techniques that combine filter-aided sample preparation and dimethyl labeling followed by liquid chromatography tandem mass spectrometry.

\section{MATERIALS AND METHODS}

\section{Materials}

Bovine milk was collected from 4 healthy, primiparous, Holstein-Friesian cows in a farm in Zaffelaere, Belgium, from August 2012 to August 2013. The cows were milked using an automatic milking system, with an average milk yield of $27.5 \pm 6.5 \mathrm{~kg} / \mathrm{d}$. No specific permissions were required for this sample collection, because samples were taken from the milk collected during regular milking. A $100-\mathrm{mL}$ sample, which was pooled milk from all 4 quarters representing an average of the whole milking, was collected at each time point. The samples were frozen immediately at $-20^{\circ} \mathrm{C}$ after collection and transferred frozen to the laboratory for protein, fat, lactose, and proteomic analysis. Samples collected at $0.5,1,2,3,6$, and 9 mo and the latest time point of the lactation (10 mo for cow 1, 11 mo for cow 2, and 12 mo for cow 3 , the latest time point was missed for cow 4) were used for this study. The colostrum samples have been analyzed and published already (Zhang et al., 2015).

\section{Milk Composition Analysis and Proteomics Techniques}

Milk samples were analyzed for SCC and protein, fat, and lactose contents with a CombiFoss 5000 at Qlip (Foss, Zutphen, the Netherlands).

The proteomics methods used in this study were based on previous articles (Hettinga et al., 2011; Lu et al., 2011; Zhang et al., 2015).

\section{Milk Serum Separation}

Milk samples collected at different time points from 4 individual cows were centrifuged at $1,500 \times g$ for 10 min at $10^{\circ} \mathrm{C}$ (Beckman Coulter Avanti J-26XP centrifuge, rotor JA-25.15, Beckman Coulter Inc., Brea, CA). The fat was removed and the obtained supernatant was transferred to the ultracentrifuge tubes followed by ultracentrifugation at $100,000 \times g$ for $90 \mathrm{~min}$ at $30^{\circ} \mathrm{C}$ (Beckman L-60, rotor $70 \mathrm{Ti}$, Beckman Coulter Inc.). After ultracentrifugation, samples were separated into 3 phases. The top layer was milk fat, the middle layer was milk serum, and the bottom layer (pellet) was casein. Milk serum was used for bicinchoninic acid (BCA) assay and filter-aided sample preparation as described below.

\section{BCA Assay}

A BCA Protein Assay Kit 23225 (Thermo Scientific Pierce, Rockford, IL) was used for protein concentration determination, according to the manufacturer's instructions. Bovine serum albumin was used as standard for making a calibration curve. The standard curve covers the protein concentration from 0.02 to $2 \mu \mathrm{g} /$ $\mu \mathrm{L}$. Subsequently, the milk serum protein concentration was determined.

\section{Filter-Aided Sample Preparation}

Milk serum samples $(20 \mu \mathrm{L})$, including samples of each time point and pooled samples of all time points from each cow, were diluted in $0.1 M$ Tris $/ \mathrm{HCl} \mathrm{pH} 8.0$ $+4 \%$ sodium dodecyl sulfate $+0.1 M$ dithiotreitol (SDT-lysis buffer) to obtain a $1 \mu \mathrm{g} / \mu \mathrm{L}$ protein solution. Samples were then incubated for $10 \mathrm{~min}$ at $95^{\circ} \mathrm{C}$ and centrifuged at 18,407 $\times g$ for 10 min after cooling down to room temperature. Twenty microliters of sample was directly added to $180 \mu \mathrm{L}$ of $0.05 M$ iodoacetamide/0.1 $M$ Tris/HCl pH $8.0+8 M$ urea (UT) in a low-binding Eppendorf tube (LoBind tubes, Hamburg, Germany) and incubated for 10 min while mildly shaking at room temperature. All of the sample was transferred to a Pall 3K omega filter (10-20 kDa cutoff, OD003C34; Pall, Washington, NY) and centrifuged at 15,871 $\times g$ for $30 \mathrm{~min}$. A total of $100 \mu \mathrm{L}$ of iodoacetamide $(0.05$ $M$ iodoacetamide in UT) was added and incubated for $10 \mathrm{~min}$ at room temperature and then centrifuged at $15,871 \times g$ for $30 \mathrm{~min}$. Three repeated centrifugations at $15,871 \times g$ for 30 min were carried out after adding $100 \mu \mathrm{L}$ of UT 3 times. After that, $110 \mu \mathrm{L}$ of 0.05 $M \mathrm{NH}_{4} \mathrm{HCO}_{3}$ in water (ABC) was added to the filter unit, and the samples were centrifuged again at 15,871 $\times g$ for $30 \mathrm{~min}$. Then, the filter was transferred to a new low-binding Eppendorf tube. A total of $100 \mu \mathrm{L}$ of $\mathrm{ABC}$ containing $0.5 \mu \mathrm{g}$ of trypsin was added followed by overnight incubation at room temperature. Finally, the sample was centrifuged at $15,871 \times g$ for $30 \mathrm{~min}$, and $3.5 \mu \mathrm{L}$ of $10 \%$ trifluoroacetic acid was added to the filtrate to adjust the $\mathrm{pH}$ value of the sample to around 2. These samples with protein $>10$ to $20 \mathrm{kDa}$ were ready for dimethyl labeling. 


\section{Dimethyl Labeling}

The trypsin-digested samples of pooled milk serum from each individual cow collected at several time points were labeled with the light reagent (using normal unlabeled formaldehyde and cyanoborohydride), whereas trypsin-digested samples of milk serum collected at each time point of each individual cow were labeled with the heavy reagent (using deuterated formaldehyde and normal cyanoborohydride). The dimethyl labeling was carried out according to Boersema et al. (2009) by oncolumn dimethyl labeling. Stage tips containing $2 \mathrm{mg}$ of LiChroprep C18 (25- $\mu$ m particles; Merck Millipore, Amsterdam, the Netherlands) column material (C18+ Stage tip) were made in house. The C18+ Stage tip column was washed 2 times with $200 \mu \mathrm{L}$ of methanol. The column was conditioned with $100 \mu \mathrm{L}$ of $1 \mathrm{~mL} / \mathrm{L}$ formic acid $(\mathbf{H C O O H})$, and then samples were loaded on the C18+ Stage tip column. The column was washed with $100 \mu \mathrm{L}$ of $1 \mathrm{~mL} / \mathrm{L} \mathrm{HCOOH}$ and then slowly flushed with $100 \mu \mathrm{L}$ of labeling reagent $\left(0.2 \% \mathrm{CH}_{2} \mathrm{O}\right.$ or $\mathrm{CD}_{2} \mathrm{O}$ and $0.03 M$ cyanoborohydride in $0.05 M$ phosphate buffer $\mathrm{pH}$ 7.5) in about $10 \mathrm{~min}$. The column was washed again with $200 \mu \mathrm{L}$ of $1 \mathrm{~mL} / \mathrm{L} \mathrm{HCOOH}$. Finally, the labeled peptides were eluted with $50 \mu \mathrm{L}$ of $70 \%$ acetonitrile/30\% $1 \mathrm{~mL} / \mathrm{L} \mathrm{HCOOH}$ from the $\mathrm{C} 18+$ Stage tip columns. The samples were then dried in a vacuum concentrator (Eppendorf Vacufuge) at $45^{\circ} \mathrm{C}$ for 20 to $30 \mathrm{~min}$ until the volume of each sample decreased to $15 \mu \mathrm{L}$ or less. The pairs of samples with light dimethyl label and heavy dimethyl label were then mixed, and the volume was adjusted to exactly $100 \mu \mathrm{L}$ by adding 1 $\mathrm{mL} / \mathrm{L} \mathrm{HCOOH}$. These samples were ready for analysis by liquid chromatography tandem mass spectrometry.

\section{Liquid Chromatography Tandem Mass Spectrometry}

Eighteen microliters of the trypsin-digested milk fractions was injected on a $0.10 \times 30 \mathrm{~mm}$ Magic $\mathrm{C} 18 \mathrm{AQ}$ 200A 5- $\mu \mathrm{m}$ beads (Michrom Bioresources Inc., Auburn, CA) preconcentration column (prepared in house) at a maximum pressure of $27,000 \mathrm{kPa}$. Peptides were eluted from the preconcentration column onto a $0.10 \times 200$ mm Prontosil 300-3-C18H (Bischoff, Germany) analytical column with an acetonitrile gradient at a flow of $0.5 \mu \mathrm{L} / \mathrm{min}$, using gradient elution from 9 to $34 \%$ acetonitrile in water with $0.5 \mathrm{vol} / \mathrm{vol} \%$ acetic acid in 50 min. The column was washed using an increase in the percentage acetonitrile to $80 \%$ (with $20 \%$ water and 0.5 $\mathrm{vol} / \mathrm{vol} \%$ acetic acid in the acetonitrile and the water) in 3 min. Between the preconcentration and analytical columns, an electrospray potential of $3.5 \mathrm{kV}$ was applied directly to the eluent via a solid $0.5-\mathrm{mm}$ platina electrode fitted into a P777 Upchurch microcross
(IDEX, Oak Harbor, WA). Full scan positive mode Fourier transform mass spectrometry (FTMS) spectra were measured between $m / z 380$ and 1,400 on an LTQOrbitrap XL (Thermo Electron, San Jose, CA). The collision-induced dissociation (CID) fragmented MS/ MS scans of the 4 most abundant doubly and triply charged peaks in the FTMS scan were recorded in datadependent mode in the linear trap (MS/MS threshold $=5.000)$.

\section{Data Analysis}

Each run with all MS/MS spectra obtained was analyzed with Maxquant 1.3.0.5 with Andromeda search engine (Cox and Mann, 2008; Cox et al., 2011). Carbamidomethylation of cysteines was set as a fixed modification (enzyme $=$ trypsin, maximally 2 missed cleavages, peptide tolerance $10 \mathrm{ppm}$, fragment ions tolerance $0.5 \mathrm{amu}$ ). Oxidation of methionine, N-terminal acetylation and deamidation of asparagine or glutamine were set as variable modification for both identification and quantification. The bovine reference database for peptides and protein searches was downloaded as FASTA files from Uniprot (http://www.uniprot.org/) with reverse sequences generated by Maxquant. A set of 31 protein sequences of common contaminants was added including trypsin (P00760, bovine), trypsin (P00761, porcine), keratin K22E (P35908, human), keratin K1C9 (P35527, human), keratin K2C1 (P04264, human), and keratin K1C1 (P35527, human). A maximum of 2 missed cleavages were allowed, and mass deviation of $0.5 \mathrm{Da}$ was set as limitation for MS/MS peaks and maximally $6 \mathrm{ppm}$ deviation on the peptide $\mathrm{m} / z$ during the main search. The false discovery rate was set to $1 \%$ on peptide and protein level. The length of peptides was set to at least 7 amino acids. Finally, proteins were displayed based on minimally 2 distinct peptides of which at least one was unique and unmodified.

Dimethyl labeling was based on doublets with dimethLys0 and dimethNter0 as light and dimethLys4 and dimethNter4 as heavy labels. Razor and unique peptides were used for quantification. Normalized H:L ratios of proteins from samples collected over time $(\mathrm{H})$ to the pooled sample of each cow (L) were used for further statistical analysis. Also, the intensity-based absolute quantification (iBAQ) algorithm was used in this research. Because this study was carried out as a follow-up to the earlier published study describing the changes in colostrum proteome (Zhang et al., 2015), the summed iBAQ of proteins based on biological function in colostrum (average of 3 time points from d 0 to 2) based on that study were also included. It estimates absolute protein concentration as the sum of all peptide intensities divided by the number of theoretically 
observable tryptic peptides. The $\mathrm{B} A \mathrm{BQ}$ value has been reported to have a reasonable correlation with known absolute protein amounts over at least 4 orders of magnitude (Schwanhausser et al., 2011).

The function of the identified proteins was checked in the UniprotKB database released March 2014 (http:// www.uniprot.org/). The correlation between the amount of total immunoglobulins and total protease inhibitors was calculated using SPSS (Version 21, IBM Corp., Armonk, NY). To select the proteins that significantly decrease over time, proteins were analyzed univariately. For each protein and per cow, a regression line was fitted on the protein concentrations measured at time points $0.5,1,2,3,6$, and $9 \mathrm{mo}$ and the latest time point of the lactation. To reliably estimate a regression line, only proteins with at least 4 observed time points per cow were considered. The regression line summarizes per cow the concentration profiles for each protein into 4 intercepts and 4 slopes. The intercepts are the protein concentration at $0.5 \mathrm{mo}$; the slopes indicate the decrease or increase in concentration between time points. By using hypothesis tests on the slopes, it can be determined whether the decrease or increase in concentration is significant. The Lilliefors normality test (Lilliefors, 1967) was used to test whether the 4 slopes were normally distributed. Proteins for which the 4 slopes were not normally distributed were discarded, because the nonparametric Wilcoxon signed rank test cannot establish a significant decrease with only 4 observations with $\alpha=0.05$. Proteins with normally distributed slopes were subjected to a 2 -sided $t$-test to test whether the slopes were significantly decreasing or increasing (with $\alpha=0.05$ ). This significant analysis has been used in our previous bovine colostrum study (Zhang et al., 2015).

\section{RESULTS}

\section{The Changes of Milk Composition over Lactation}

Figure 1 shows the changes of protein, fat, and lactose content of milk samples as well as milk yield over lactation. Milk yield and lactose increased from colostrum to $3 \mathrm{mo}$ and slightly decreased afterward. Milk protein and fat content decreased from colostrum to $0.5 \mathrm{mo}$. Both components were relatively constant in mid lactation before a slightly decrease in late lactation (Figure 1). The average SCC of milk samples was relatively higher $(60,000$ cells $/ \mathrm{mL})$ in early and late lactation, compared with mid lactation $(37,000$ cells/ $\mathrm{mL}$ ). The SCC of all milk samples was below 130,000 cells/mL. Udder health in terms of microbiological milk analysis was not performed.

\section{Overview of the Identified Proteins and Quantified Proteins in 4 Individual Cows}

A total of 229 proteins were identified in this study, of which 219 could be quantified. For the 4 individual cows, around 220 proteins were identified in each individual cow, and $80 \%$ of these proteins could be identified and quantified in all 4 cows. Besides these similar identified and quantified proteins, differences also existed between the 4 individual cows. For example, some proteins could only be identified and quantified in one cow as shown in the Venn diagram (Supplementary Figure S1; http://dx.doi.org/10.3168/jds.2015-9342). In addition, the number of identified and quantified proteins at early and late lactation stage are also different among the 4 individual cows, whereas they are quite similar at middle lactation stage ( 3 and 6 mo; data not shown).

\section{Distribution of Identified and Quantified Proteins over Biological Functions}

Table 1 shows the distribution of identified proteins based on their biological functions according to Uniprot. Enzymes (19\%), immune-related proteins (18\%), and transport proteins (15\%) were the 3 dominant groups. Distribution of biological functions slight changed over lactation (less than 10\%, data not shown). The summed iBAQ value of quantified proteins based on the biological functions changed to a much larger extent than the number of proteins from colostrum to late lactation (Figure 2). Because this study was carried out as a follow-up to the earlier published study describing the changes in colostrum proteome (Zhang et al., 2015), the summed iBAQ of proteins based on biological function in colostrum (average of 3 time points from d 0 to 2 ) based on that study were also included in Figure 2. Transport and immune-related proteins decreased remarkably from colostrum to $0.5 \mathrm{mo}$, followed by an approximately 1.5 -fold increase from 0.5 to 6 mo. Similar trends could be found for protease inhibitors (Figure 2). On the contrary, enzymes increased from colostrum to mature milk. The 3 groups, immunity, transport, and enzymes, all increased from 0.5 to 6 mo of lactation. The increase of transport proteins from 0.5 to $3 \mathrm{mo}$ is comparable to the change in milk yield during that period (Figure 2). In fact, the changes in the summed iBAQ value during that period were almost completely caused by the 3 most abundant proteins of each biological-function group, as shown in Table 1. For instance, the increase of 2 dominant groups, enzymes and transport proteins, were mainly due to the increase of $\alpha-\mathrm{LA}$, ribonuclease pancreatic, $\beta$-1,4-galactosyltransferase 1 , 


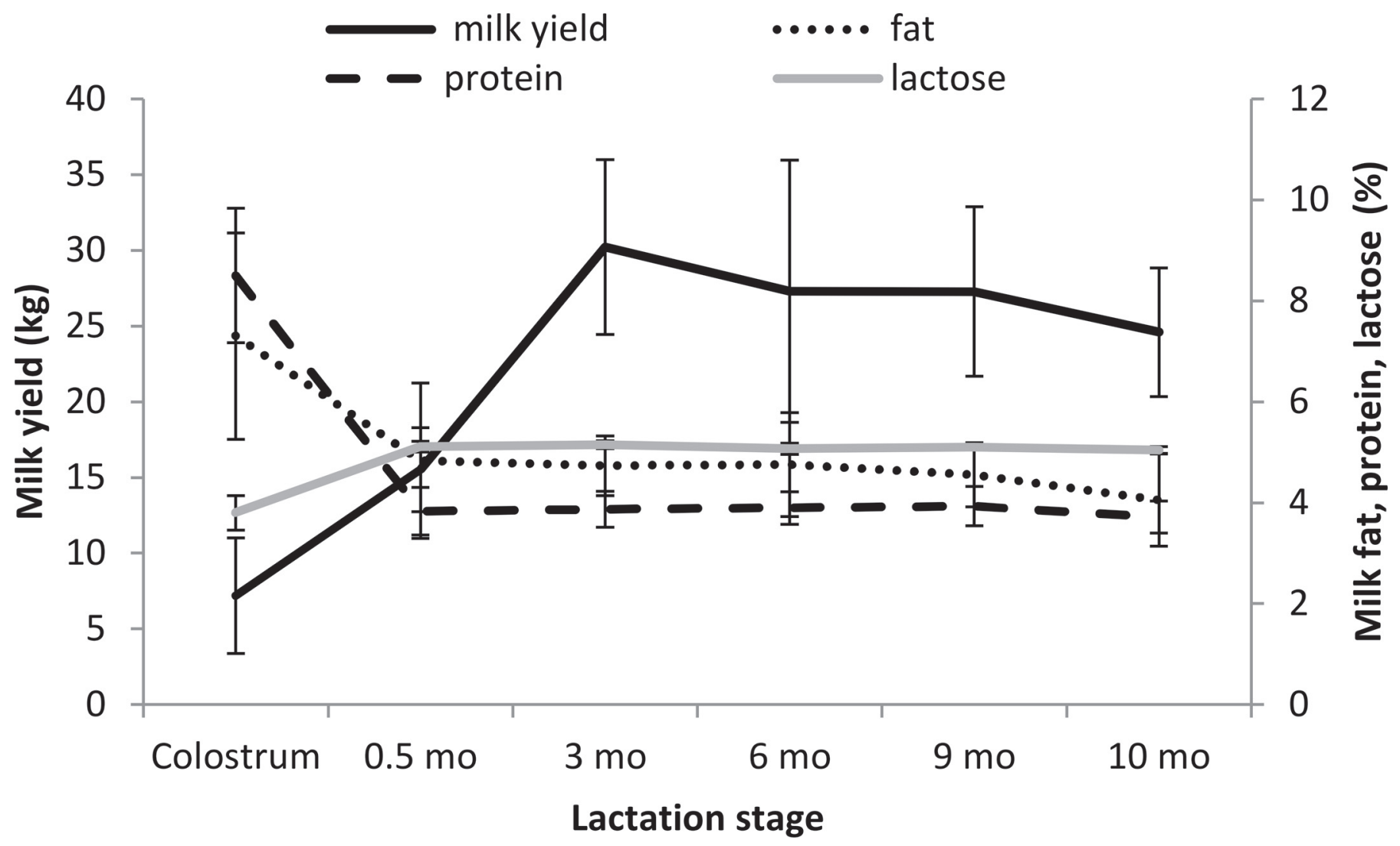

Figure 1. The changes of milk yield and fat, protein, and lactose percentages over lactation. Error bars show SD of the values for the 4 individual cows.

and $\beta$-LG. The 3 most abundant proteins represented $99.6 \%$ of summed iBAQ value in the enzyme group and $90.7 \%$ of summed iBAQ value in the transport group.

\section{The Quantitative Changes of Proteins in 4 Individual Cows over Lactation}

Next to the changes of summed iBAQ values based on each biological function, the changes of each specific protein were also obtained as shown in Supplementary Table S1 (http://dx.doi.org/10.3168/jds.2015-9342). Figure 3 shows changes of proteins related to lipid synthesis and transport, and proteins related to lactose synthesis in 4 individual cows over lactation, such as fatty acid-binding protein (FABP3), epididymal secretory protein E1 (NPC2), perilipin-2 (PLIN2), butyrophilin subfamily 1 member A1 (BTN1A1), apolipoprotein E (APOE), $\alpha$-LA, and $\beta$-1,4-galactosyltransferase 1. And for the changes of blood coagulation proteins, protease inhibitors as well as both innate and adaptive immunerelated proteins, including polymeric immunoglobulin receptor, immunoglobulins (IGLL1), lactoperoxidase, $\alpha$-1-acid glycoprotein, lactoferrin (LTF), and comple- ment proteins, are shown in Figure 3. Proteins participating in the complement and coagulation cascade showed a similar trend over lactation (blue box in Figure 3). Also the immunoglobulins and protease inhibitors changed comparably over lactation (green box in Figure 3). A linear regression between the amount of total immunoglobulins and total protease inhibitors was established after testing for heteroscedasticity and normal distribution. The result showed that immunoglobulins and protease inhibitors were highly correlated $(\mathrm{r}=0.69, P<0.05)$.

Of the quantified proteins, 95 proteins were determined at least at 4 time points per cow. This was deemed as a minimal requirement to reliably estimate the trend over time. The concentration profiles of these 95 proteins were summarized into intercepts and slopes as described in the methods section. The Lilliefors test indicated that 5 proteins had not normally distributed slopes, so these proteins were discarded. From the 90 proteins with normally distributed slopes, a total of 33 proteins showed a significant increase or decrease, and they are listed in Table 2. Table 2 also shows the biological functions and subcellular locations of these signifi- 
Table 1. Distribution of identified milk serum proteins over biological functions, and intensity-based absolute quantification (iBAQ value) of the 3 most dominant proteins per biological function

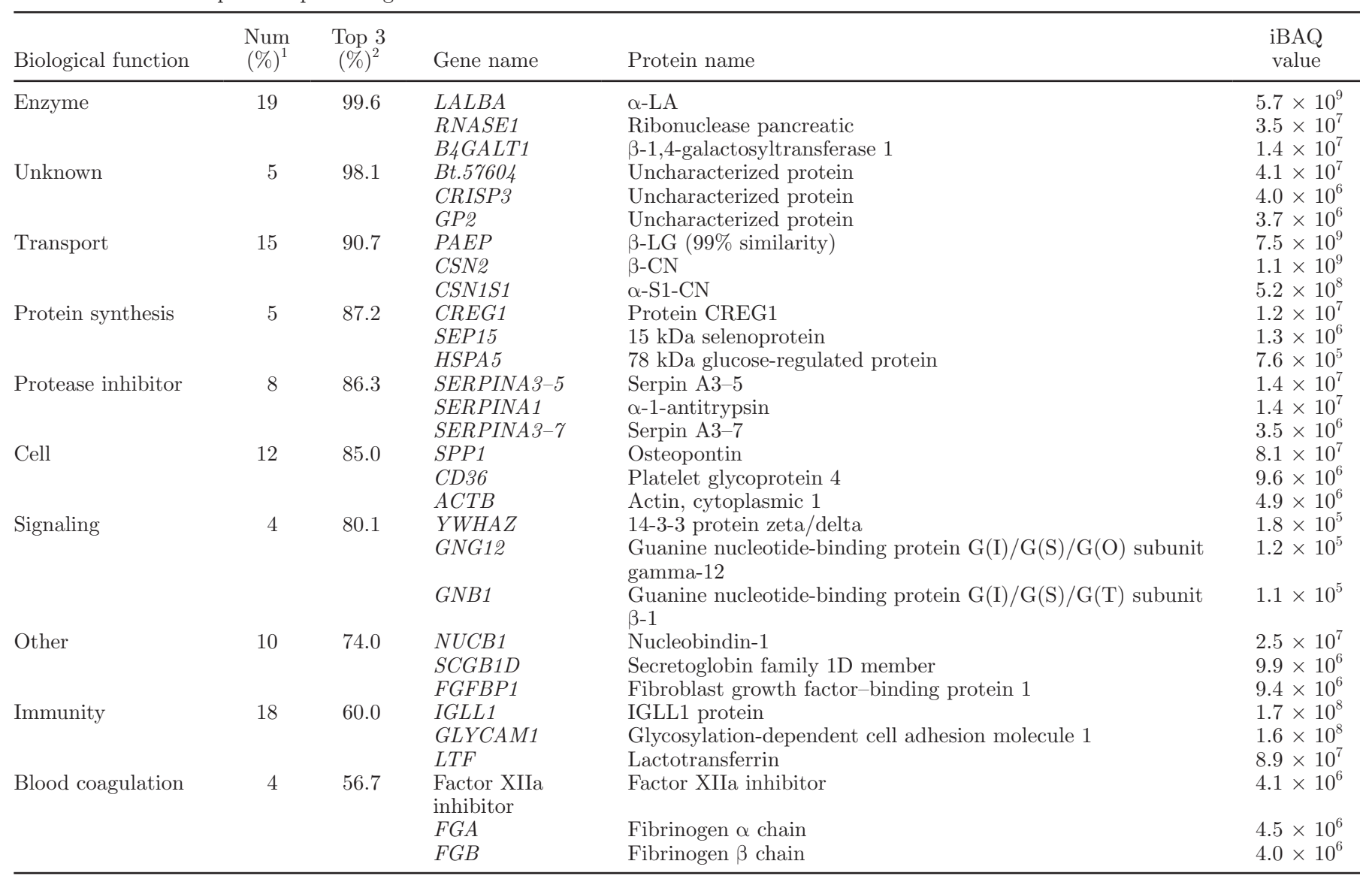

${ }^{1} \mathrm{Num}=$ the percentage of identified proteins per biological function out of the total number of identified proteins.

${ }^{2}$ Top 3 = the summed iBAQ value of the three most abundant proteins per biological function as a percentage of the total summed iBAQ of all protein per biological function.

cantly different proteins. Immune-related proteins were the largest group among the changed proteins $(33 \%$ of all significantly different proteins), and they decreased rapidly from early lactation to middle lactation. The significantly changed immune-related proteins are shown in Figure 3. Transport proteins followed, accounting for $27 \%$ of the significantly changed proteins. Except for caseins, most of them were related to lipid secretion and transport (epididymal secretory protein E1, BTN1A1, PLIN2, APOE; Figure 3). However, the changes of these proteins over lactation were different between the individual animals. Cow 1 and cow 4 had high concentrations of complement proteins at $0.5 \mathrm{mo}$, which decreased rapidly in middle lactation (blue box in Figure 3). Cow 2 and cow 3, on the other hand, had low concentrations of complement proteins at $0.5 \mathrm{mo}$, which increased gradually afterward. Although immunoglobulins decreased from early to middle lactation in all 4 cows, the rate of this decrease was much faster in cow 1 and cow 4 compared with cow 2 and cow 3 , as shown in green box in Figure 3.

\section{DISCUSSION}

This study assessed the qualitative and quantitative variation of the bovine milk proteome in 4 individual cows from 0.5 mo to the end of lactation. The small differences found in the number of identified and quantified proteins among the 4 individual cows (Supplementary Figure S1; http://dx.doi.org/10.3168/ jds.2015-9342) are in accordance with data we previously collected for colostrum (Zhang et al., 2015), using samples from the same cows. The apparent presence of unique proteins in individual cows (Supplementary Figure S1) is not caused by differences in SCC because they are much lower than the threshold (250,000 cells/ $\mathrm{mL}$ ) of subclinical mastitis (Turk et al., 2012). However, it could be because of both the detection limit of 


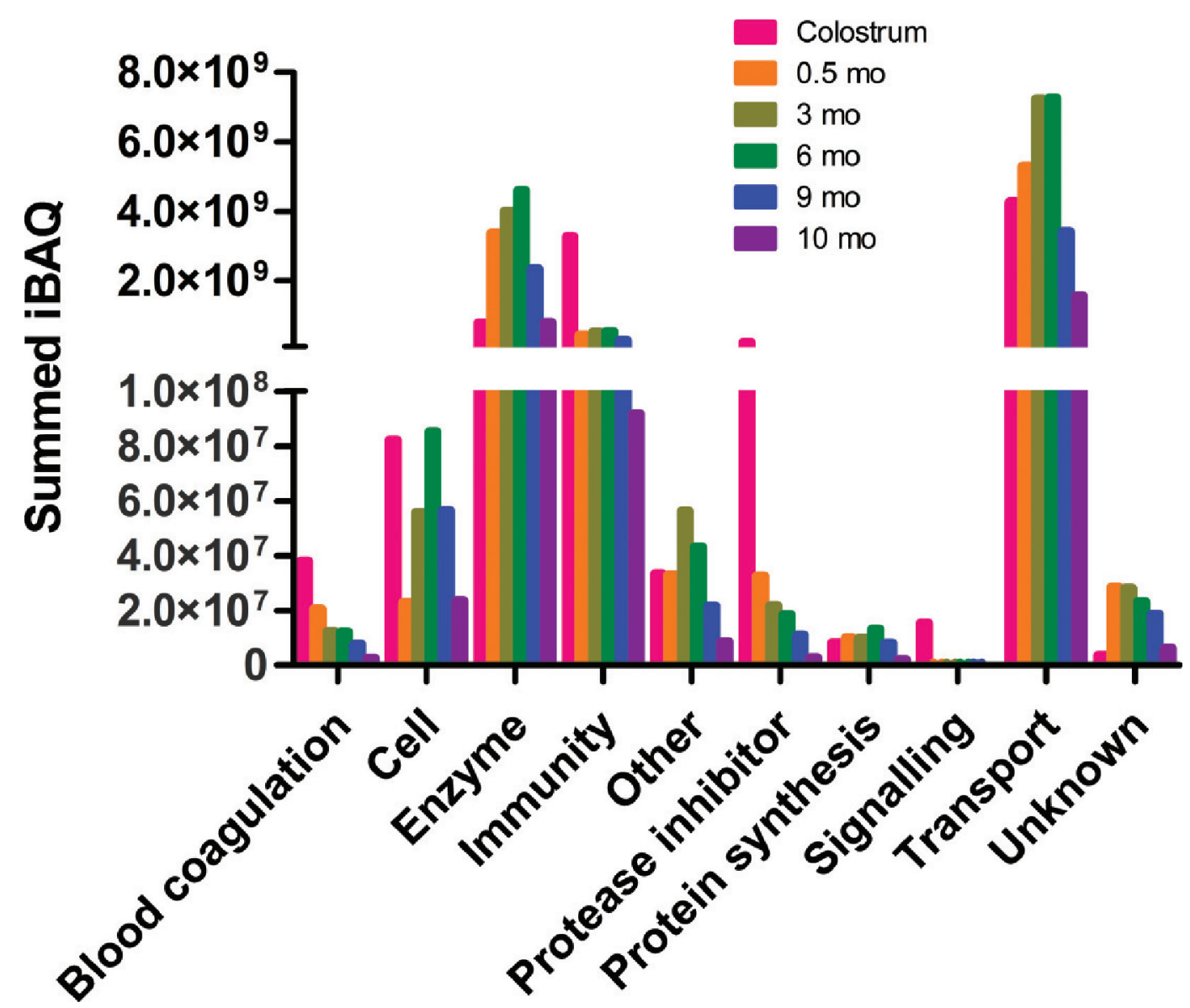

Figure 2. Quantitative changes of milk serum proteins based on biological functions over lactation stage (Cell includes cell motility, cell apoptosis, cell growth, cytoskeleton, cell adhesion, cell differentiation, cell proliferation, cell shape; Immunity includes immune response, complement, antibacterial, host defense, acute phase, antigen binding). iBAQ = intensity-based absolute quantification. Color version available online.

the instrument or differences between individual cows (e.g., age or parity). Because most unique proteins have only 2 identified peptides at relatively low intensity, we assume the unique proteins are due to the detection limit. The summed iBAQ values of proteins for each biological function changed considerably from early to late lactation (Figure 2), especially for the functions of enzyme, transport, and immunity, showing that variation was more on a quantitative than a qualitative level. At the same time, we need to acknowledge that the data interpretation is limited by the small sample size $(\mathrm{n}=4)$, and it is unknown how well these 4 cows represent the full variation that can be expected between cows. Nevertheless, the data give a first insight in the qualitative and quantitative changes between cows over lactation.

The increase of iBAQ value in enzyme group is mainly caused by the large increase in $\alpha$-LA and $\beta-1,4-$ galactosyltransferase 1 (Table 1 ). Both these proteins play an important role in the synthesis of lactose
(Landers et al., 2009), which coincides with higher synthesis of lactose in middle lactation compared with 0.5 mo. Ribonuclease pancreatic, which is another highabundant enzyme, is involved in degrading bacterial RNA and nutrient uptake in the intestinal tract and is especially important for plant-eating animals such as cows (Liu et al., 2014). The relative high concentration of ribonuclease pancreatic in this early-lactation stage may be related to the immature digestion system of calves in the early lactation.

\section{Lipid Synthesis and Transport Proteins}

In addition to the changes of dominant transport proteins, other transport proteins also changed as lactation advanced (Figure 3). Protein FABP3 has been known to be highly abundant in the bovine mammary gland (Bionaz and Loor, 2008). It transports endothelial long-chain fatty acids to the endoplasmic reticulum 


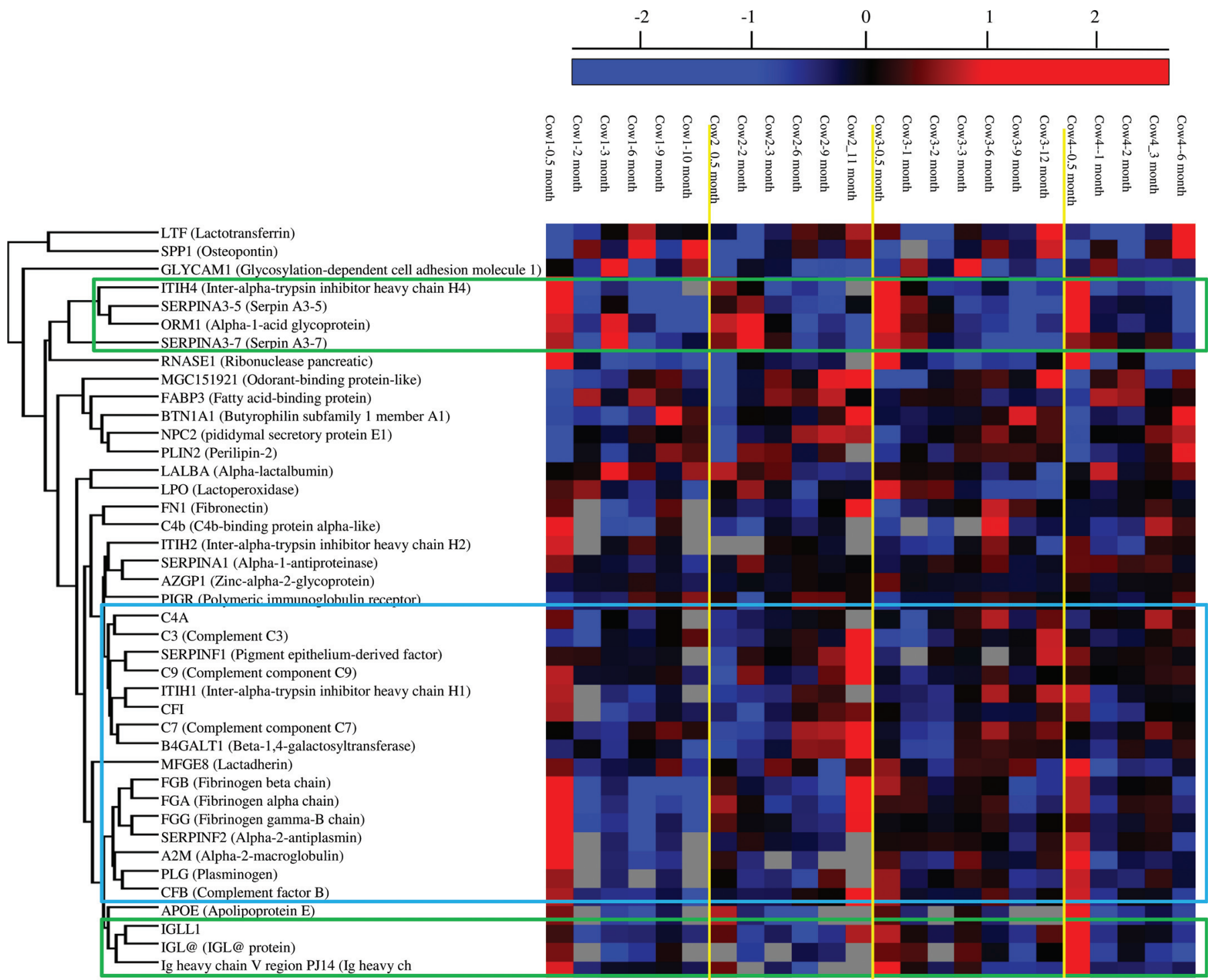

Figure 3. Quantitative changes ( $\log _{2}$ ratio) of milk serum proteins in 4 individual cows over lactation, showing proteins related to milk synthesis and secretion, lactose synthesis, as well as complement proteins, blood coagulation, and protease inhibitors. The blue box includes proteins participating in the complement and coagulation cascade, and the green box includes immunoglobulins and protease inhibitors.

for the synthesis of triglycerides that are eventually incorporated into lipid droplets for secretion (Bionaz and Loor, 2008). Protein FABP3 increased from 0.5 mo to middle lactation (Figure 3), which agrees with the gene expression level of FABP3 during lactation (Bionaz et al., 2012). Proteins BTN1A1 and PLIN2, which play an important role in the milk fat synthesis (Bionaz and Loor, 2008), were both significantly increased $(P<0.05)$ (Table 2). The increase of FABP3, BTN1A1, and PLIN2 in bovine milk (Figure 3) suggests an increased de novo mammary fatty acid synthesis as lactation advances, which is similar to the change of these proteins in human milk (Zhang et al., 2013). The increase of these proteins from 0.5 mo to middle lacta- tion correlates with milk fat yield (Figure 1) and may, therefore, be a potential indicator for metabolic activity in the mammary gland. On the contrary, APOE significantly decreased over lactation $(P<0.05)$, which is a cholesterol transporter (Friedland et al., 2003). Cholesterol plays an important role in the synthesis of vitamin D and the steroid hormones (Berg et al., 2002), which is critical to the development of the newborn. The decrease of APOE from 0.5 mo to middle lactation in this study is in agreement with what was found in human milk (Zhang et al., 2013). The high concentration of APOE in early lactation (Figure 3 ) indicates the importance of cholesterol in the development of the neonate. 
Table 2. Significantly different milk serum proteins over lactation

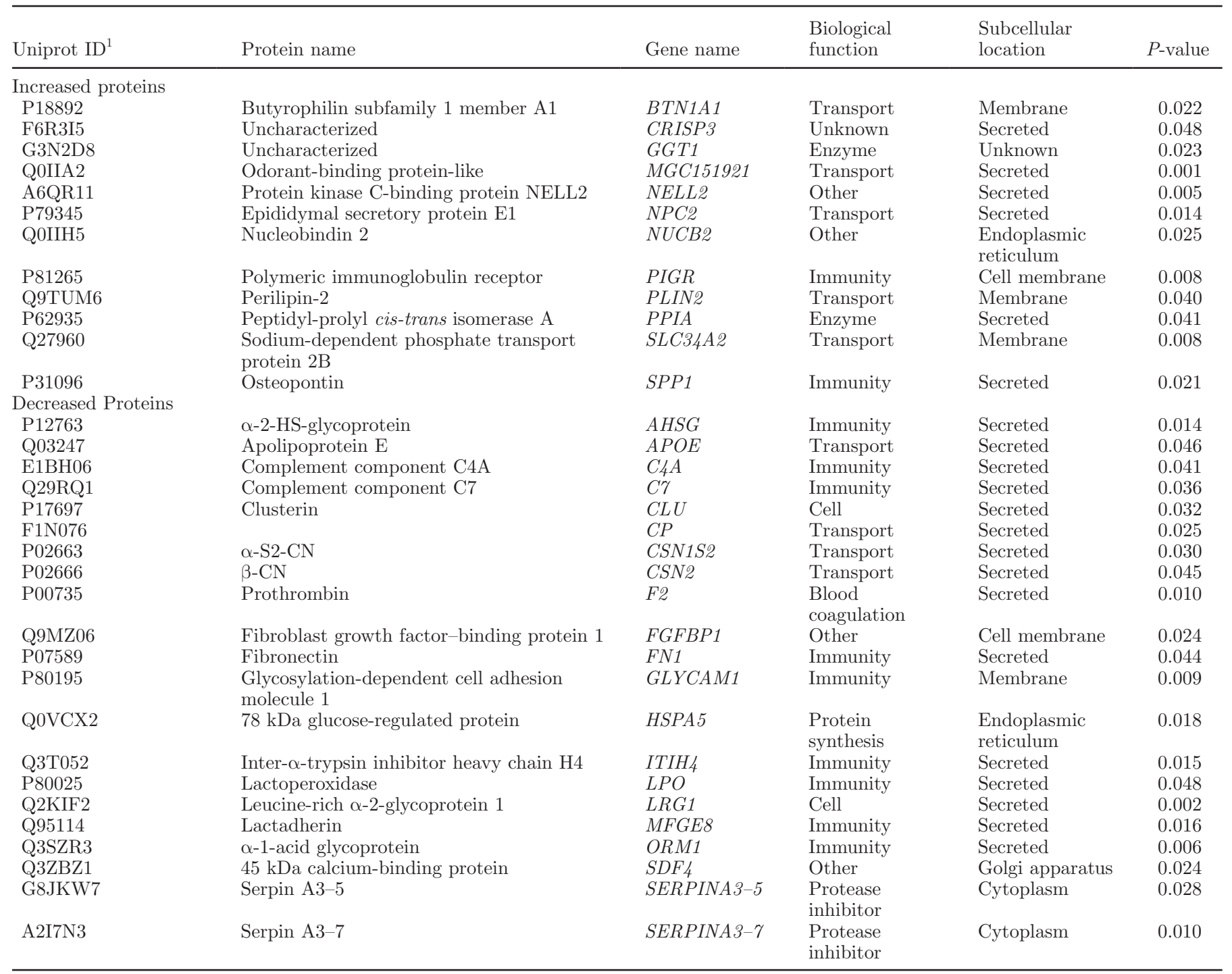

${ }^{1}$ Uniprot ID (http://www.uniprot.org/).

\section{Immune-Related Proteins}

Next to the changes in proteins related to milk synthesis and secretion, immune-related proteins also showed large changes over lactation (Figure 3). The high concentration of immune-related proteins is consistent with the result in a bovine colostrum study (Zhang et al., 2015), which can be related to the role of these proteins in the maturation of the immune system of calves. The steady increase of these proteins during late lactation (Figure 3) is also in line with other studies (Lefevre et al., 2007). The correlation between immunoglobulins and protease inhibitors is in line with the correlation between immune-related proteins and protease inhibitors as described before for colostrum (Zhang et al., 2015). This corresponds with the hypoth- esis given in that paper that protease inhibitors play a role in the protection of immunoglobulins and thus promote maturation of the newborn's immune system. Our results, however, show different changes over lactation of proteins related to the innate immune system and the adaptive immune system. The differences between the 2 groups of immune proteins among 4 individual cows from 2 to 6 mo (as shown in Figure 3, innate immune proteins in the blue box and adaptive immune proteins in the green box) may be mainly associated with differences in their immune response phenotypes caused by genotype, and age. Gamma delta T-cell receptor lymphocyte subpopulations have been reported differentially distributed in blood and spleen between young and adult cattle (Wyatt et al., 1994). Individual cows have been shown to respond differently in adap- 
tive immune response (B-cell regulated) and in innate immune response (T-cell regulated) after immunization (Hine et al., 2012). The changes of innate immune proteins may be related to the regulation of $\mathrm{T}$ cells during the immune response (Kwan et al., 2012), whereas the changes of adaptive immune proteins is related to the secretion of B cells (Mauri and Bosma, 2012).

With respect to the specific immune-related proteins, glycosylation-dependent cell adhesion molecule $1(P<$ 0.05 ) decreased significantly (Table 2). It is the most abundant protein after exclusion of major milk proteins, which is consistent with a previous proteomics study of bovine milk (Hettinga et al., 2011). The high abundance of glycosylation-dependent cell adhesion molecule 1 was suggested to be related to its important role in the host defense of the neonate. Lactoferrin, another relatively high-abundant protein, is an ironbinding protein with antimicrobial activity (Riley et al., 2008). The concentration of LTF was low at 0.5 mo and progressively increased as lactation advanced (Figure 3), which was also previously reported (Cheng et al., 2008). The relative high concentration of LTF has been related to its protective role in the host defense of the neonate (Riley et al., 2008). Osteopontin (SPP1) changed similarly as LTF over lactation (Figure 3). The increase of SPP1 from 2 wk to middle lactation found in this study is similar to what was found in human milk (Lonnerdal, 2014). Osteopontin is a phosphorylated acidic glycoprotein that has been implicated in several physiological and pathological processes, including immune activation, wound healing, angiogenesis, bone remodeling, cell migration, and invasion of mammary epithelial cells (Ashkar et al., 2000; Denhardt et al., 2001; Hubbard et al., 2013). The addition of bovine SPP1 to infant formula changed expression of genes related to galactose metabolism, immune response, growth, and development toward a profile more similar to that in breastfed infants (Lonnerdal, 2014). Similar to the decrease of immunoglobulins, the increase of these immune-related proteins from early lactation to middle lactation reflect their protection on the neonate as well as their importance in the maturation of the immune system of the neonate.

\section{Preparation for Involution of Mammary Gland}

From 9 mo to the last time point of late lactation, milk yield declined during the preparation for the involution of mammary gland as shown in Figure 1, which agrees with a previous study of Piantoni et al. (2010). A rapid decline in proteins related to milk fat synthesis (PLIN2, FABP3, BTN1A1), as shown in Figure 3, corresponds to the decrease in milk fat content, as shown in Figure 1. The decrease of PLIN2, FABP3, BTN1A1, and $\alpha$-LA is in line with what was found in studies on the gene expression (Piantoni et al., 2010) and transcripts level (Boutinaud et al., 2013) in the bovine mammary gland during involution. The decrease of these proteins may aid or even accelerate mammary gland involution (Ollier et al., 2013).

In addition, mammary gland involution also requires the remodeling of mammary epithelial cells of all mammary tissue (Piantoni et al., 2010). Because mammary gland remodeling is a challenging process, during which the mammary gland is highly susceptible to new intramammary infections (Dingwell et al., 2003), protection of the mammary gland through secretion of immunerelated proteins is expected. The present study indeed shows such an upregulation of immune-related proteins in late lactation, including complement C3 (C3), IGLL1, SPP1, and LTF (Figure 3), which is also in accordance with results of previous studies (Riley et al., 2008; Wickramasinghe et al., 2012; Zhang et al., 2013). This increase in immune-related proteins may be caused by the proinflammatory state of the mammary epithelial cells during preparation for involution (Riley et al., 2008). In the classic component pathway, complement $\mathrm{C} 5$ is formed by $\mathrm{C} 3$, and it can recruit complement C9 to form the membrane attached complex on the microbial surfaces during cytolysis, which plays an important role in complement cascade (Zhang et al., 2013). Immunoglobulin G is the strongest mediator of the classical complement pathway via increased formation of the pathogen-IgG-C1 complex (Zhang et al., 2013). The increase of IGLL1 and C3 in late lactation indicates their joint role in protecting the mammary gland against infections. Osteopontin could act as a macrophage chemotactic factor for recruitment at the inflammatory sites (O'Brien et al., 2011) and as a candidate mediator of wound healing during mammarygland involution in rat mammary glands (O'Brien et al., 2012). Lactoferrin was reported to assist in the involution process by reducing viability of bovine mammary epithelial cells and inhibiting synthesis of caseins by a mechanism involving IL-1 $\beta$ (Riley et al., 2008). The increase of LTF in late lactation may also be related to its protective role in the bovine mammary gland against infections during early involution because of its known antibacterial role (Riley et al., 2008). The upregulation of immune-related proteins and downregulation of proteins involved in milk component synthesis and secretion correspond to the physiological changes that are expected to occur in the bovine mammary gland during preparation for involution. In addition, the changes in the concentration of immune-related proteins over the course of lactation as presented here could also be useful for distinguishing proteins that are modulated in response to disease. This may thereby 
aid in developing biomarker for diseases, because the natural variability of these low-abundant proteins has not been described before.

\section{CONCLUSIONS}

Although some qualitative and quantitative differences exist in the milk proteome between individual cows, their changes over lactation are similar between cows. The changes of proteins involved in lipid synthesis are similar to the changes in lipid yield over lactation, and the differences in the changes of lipid synthesis and transport proteins suggest different sources of milk fat are used at different lactation stages. Moreover, the relatively high abundance of immune-related proteins also reinforces the important role of immune-related proteins in the growth and development of calves. In addition, the increase of immune-related proteins and the decrease of proteins related to milk synthesis and secretion in late lactation not only suggests their role in protection of the mammary gland but also indicates physiological changes that occur in the bovine mammary gland during preparation for involution.

\section{REFERENCES}

Ashkar, S., G. F. Weber, V. Panoutsakopoulou, M. E. Sanchirico, M. Jansson, S. Zawaideh, S. R. Rittling, D. T. Denhardt, M. J. Glimcher, and H. Cantor. 2000. Eta-1 (osteopontin): An early component of type-1 (cell-mediated) immunity. Science 287:860-864.

Berg, J. M., J. L. Tymoczko, and L. Stryer. 2002. Important derivatives of cholesterol include bile salts and steroid hormones. Section 26.4 in Biochemistry. 5th ed. W H Freeman, New York, NY.

Bionaz, M., W. Hurley, and J. Loor. 2012. Milk protein synthesis in the lactating mammary gland: Insights from transcriptomics analyses. Chapter 11 in Milk Protein. W. L. Hurley, ed. InTech, Rijeka, Croatia.

Bionaz, M., and J. J. Loor. 2008. Gene networks driving bovine milk fat synthesis during the lactation cycle. BMC Genomics 9:366.

Boersema, P. J., R. Raijmakers, S. Lemeer, S. Mohammed, and A. J. Heck. 2009. Multiplex peptide stable isotope dimethyl labeling for quantitative proteomics. Nat. Protoc. 4:484-494.

Boutinaud, M., L. Galio, V. Lollivier, L. Finot, S. Wiart, D. Esquerre, and E. Devinoy. 2013. Unilateral once daily milking locally induces differential gene expression in both mammary tissue and milk epithelial cells revealing mammary remodeling. Physiol. Genomics 45:973-985.

Casado, B., M. Affolter, and M. Kussmann. 2009. OMICS-rooted studies of milk proteins, oligosaccharides and lipids. J. Proteomics 73:196-208.

Cheng, J. B., J. Q. Wang, D. P. Bu, G. L. Liu, C. G. Zhang, H. Y. Wei, L. Y. Zhou, and J. Z. Wang. 2008. Factors affecting the lactoferrin concentration in bovine milk. J. Dairy Sci. 91:970-976.

Cox, J., and M. Mann. 2008. MaxQuant enables high peptide identification rates, individualized p.p.b.-range mass accuracies and proteome-wide protein quantification. Nat. Biotechnol. 26:13671372.

Cox, J., N. Neuhauser, A. Michalski, R. A. Scheltema, J. V. Olsen, and M. Mann. 2011. Andromeda: A peptide search engine integrated into the MaxQuant environment. J. Proteome Res. 10:1794-1805.

D'Alessandro, A., L. Zolla, and A. Scaloni. 2011. The bovine milk proteome: Cherishing, nourishing and fostering molecular com- plexity. An interactomics and functional overview. Mol. Biosyst. 7:579-597.

D'Auria, E., C. Agostoni, M. Giovannini, E. Riva, R. Zetterstrom, R. Fortin, G. F. Greppi, L. Bonizzi, and P. Roncada. 2005. Proteomic evaluation of milk from different mammalian species as a substitute for breast milk. Acta Paediatrica. Int. J. Pediatr. 94:1708-1713.

Denhardt, D. T., M. Noda, A. W. O'Regan, D. Pavlin, and J. S. Berman. 2001. Osteopontin as a means to cope with environmental insults: Regulation of inflammation, tissue remodeling, and cell survival. J. Clin. Invest. 107:1055-1061.

Dewey, K. G. 2001. Nutrition, growth, and complementary feeding of the breastfed infant. Pediatr. Clin. North Am. 48:87-104.

Dingwell, R. T., D. F. Kelton, and K. E. Leslie. 2003. Management of the dry cow in control of peripartum disease and mastitis. Vet. Clin. North Am. Food Anim. Pract. 19:235-265.

Friedland, N., H.-L. Liou, P. Lobel, and A. M. Stock. 2003. Structure of a cholesterol-binding protein deficient in Niemann-Pick type C2 disease. Proc. Natl. Acad. Sci. USA 100:2512-2517.

German, J. B., and C. J. Dillard. 2006. Composition, structure and absorption of milk lipids: A source of energy, fat-soluble nutrients and bioactive molecules. Crit. Rev. Food Sci. Nutr. 46:57-92.

Hernell, O. 2011. Human milk vs. cow's milk and the evolution of infant formulas. Pages 17-28 in Nestle Nutrition Workshop Series: Pediatric Program. Vol. 67. S. Karger AG, Basel, Switzerland.

Hettinga, K., H. van Valenberg, S. de Vries, S. Boeren, T. van Hooijdonk, J. van Arendonk, and J. Vervoort. 2011. The host defense proteome of human and bovine milk. PLoS ONE 6:e19433.

Hine, B. C., S. L. Cartwright, and B. A. Mallard. 2012. Analysis of leukocyte populations in Canadian Holsteins classified as high or low immune responders for antibody- or cell-mediated immune response. Can. J. Vet. Res. 76:149-156.

Hubbard, N. E., Q. J. Chen, L. K. Sickafoose, M. B. Wood, J. P. Gregg, N. M. Abrahamsson, J. A. Engelberg, J. E. Walls, and A. D. Borowsky. 2013. Transgenic mammary epithelial osteopontin (spp1) expression induces proliferation and alveologenesis. Genes Cancer 4:201-212.

Kwan, W. H., W. van der Touw, and P. S. Heeger. 2012. Complement regulation of $\mathrm{T}$ cell immunity. Immunol. Res. 54:247-253.

Landers, E. A., H. R. Burkin, G. T. Bleck, L. Howell-Skalla, and D. J. Miller. 2009. Porcine beta1,4-galactosyltransferase-I sequence and expression. Reprod. Domest. Anim. 44:228-234.

Lefevre, C. M., M. R. Digby, J. C. Whitley, Y. Strahm, and K. R. Nicholas. 2007. Lactation transcriptomics in the Australian marsupial, Macropus eugenii: Transcript sequencing and quantification. BMC Genomics 8:417.

Lilliefors, H. 1967. On the Kolmogorov-Smirnov test for normality with mean and variance unknown. J. Am. Stat. Assoc. 62:399 402.

Liu, J., X. P. Wang, S. Cho, B. K. Lim, D. M. Irwin, O. A. Ryder, Y. P. Zhang, and L. Yu. 2014. Evolutionary and functional novelty of pancreatic ribonuclease: A study of Musteloidea (order Carnivora). Sci. Rep. 4:5070.

Lonnerdal, B. 2010. Bioactive proteins in human milk: Mechanisms of action. J. Pediatr. 156:S26-S30.

Lonnerdal, B. 2014. Infant formula and infant nutrition: Bioactive proteins of human milk and implications for composition of infant formulas. Am. J. Clin. Nutr. 99:712S-717S

Lu, J., S. Boeren, S. C. de Vries, H. J. van Valenberg, J. Vervoort, and K. Hettinga. 2011. Filter-aided sample preparation with dimethyl labeling to identify and quantify milk fat globule membrane proteins. J. Proteomics 75:34-43.

Mauri, C., and A. Bosma. 2012. Immune regulatory function of B cells. Annu. Rev. Immunol. 30:221-241.

Nissen, A., E. Bendixen, K. L. Ingvartsen, and C. M. Rontved. 2012 In-depth analysis of low abundant proteins in bovine colostrum using different fractionation techniques. Proteomics 12:2866-2878.

O'Brien, J., K. Hansen, D. Barkan, J. Green, P. Schedin, J. O'Brien, K. Hansen, D. Barkan, J. Green, and P. Schedin. 2011. Non-steroidal anti-inflammatory drugs target the pro-tumorigenic extra- 
cellular matrix of the postpartum mammary gland. Int. J. Dev. Biol. 55:745-755.

O'Brien, J. H., L. A. Vanderlinden, P. J. Schedin, and K. C. Hansen. 2012. Rat mammary extracellular matrix composition and response to ibuprofen treatment during postpartum involution by differential GeLC-MS/MS analysis. J. Proteome Res. 11:48944905.

Ollier, S., X. Zhao, and P. Lacasse. 2013. Effect of prolactin-release inhibition on milk production and mammary gland involution at drying-off in cows. J. Dairy Sci. 96:335-343.

Piantoni, P., P. Wang, J. K. Drackley, W. L. Hurley, and J. J. Loor. 2010. Expression of metabolic, tissue remodeling, oxidative stress, and inflammatory pathways in mammary tissue during involution in lactating dairy cows. Bioinform. Biol. Insights 4:85-97.

Riley, L. G., P. Williamson, P. C. Wynn, and P. A. Sheehy. 2008. Lactoferrin decreases primary bovine mammary epithelial cell viability and casein expression. J. Dairy Res. 75:135-141.

Sacerdote, P., F. Mussano, S. Franchi, A. E. Panerai, G. Bussolati, S. Carossa, A. Bartorelli, and B. Bussolati. 2013. Biological components in a standardized derivative of bovine colostrum. J. Dairy Sci. 96:1745-1754.

Schwanhausser, B., D. Busse, N. Li, G. Dittmar, J. Schuchhardt, J. Wolf, W. Chen, and M. Selbach. 2011. Global quantification of mammalian gene expression control. Nature 473:337-342.
Stelwagen, K., E. Carpenter, B. Haigh, A. Hodgkinson, and T. T. Wheeler. 2009. Immune components of bovine colostrum and milk. J. Anim. Sci. 87:3-9.

Turk, R., C. Piras, M. Kovacic, M. Samardzija, H. Ahmed, M. De Canio, A. Urbani, Z. F. Mestric, A. Soggiu, L. Bonizzi, and P. Roncada. 2012. Proteomics of inflammatory and oxidative stress response in cows with subclinical and clinical mastitis. J. Proteomics 75:4412-4428.

Wickramasinghe, S., G. Rincon, A. Islas-Trejo, and J. F. Medrano. 2012. Transcriptional profiling of bovine milk using RNA sequencing. BMC Genomics 13:45.

Wyatt, C. R., C. Madruga, C. Cluff, S. Parish, M. J. Hamilton, W. Goff, and W. C. Davis. 1994. Differential distribution of gamma delta T-cell receptor lymphocyte subpopulations in blood and spleen of young and adult cattle. Vet. Immunol. Immunopathol. 40:187-199.

Zhang, L., S. Boeren, J. A. Hageman, T. van Hooijdonk, J. Vervoort, and K. Hettinga. 2015. Bovine milk proteome in the first 9 days: Protein interactions in maturation of the immune and digestive system of the newborn. PLoS ONE 10:e0116710.

Zhang, Q., J. Cundiff, S. Maria, R. McMahon, J. Woo, B. Davidson, and A. Morrow. 2013. Quantitative analysis of the human milk whey proteome reveals developing milk and mammary-gland functions across the first year of lactation. Proteomes 1:128-158. 